\title{
HEGEMONI KETUA PARTAI TERHADAP PRESIDEN DALAM MAJALAH TEMPO EDISI 13 - 19 APRIL 2015 (STUDI ANALISIS WACANA KRITIS)
}

\author{
Moh. Khalid Hasan; Ali Nuke Affandy \\ Universitas Muhammadiyah Surabaya \\ kholid@gmail.com
}

ABSTRAK

ABSTRACT
Tujuan penelitian ini adalah mendeskripsikan hegemoni Jokowi Mega berdasarkan dimensi (1) tekstual (mikrostruktural), (2) kewacanaan (mesostruktural), (3) sosial-budaya (makrostruktural) pada majalah Tempo edisi 13-19 April 2015. Jenis penelitian ini adalah penelitian kualitatif. Penelitian ini menggunakan pendekatan analaisis wacana kritis (AWK). Menurut Darma (2013:54), bahasan AWK berfokus pada sifat alami kontekstualisasi idiologi. Pendekatan pada idiologi harus memperhatikan efeknya terhadap bentuk dan makna serta struktur wacana yang kelak berperan untuk dan mentranformasi idiologi. Idiologi juga berpengaruh pada pemakaian bahasa yang digunakan dalam kontruksi wacana, termasuk pengelompokan dan penafsiran situasi sosial. Berdasarkan hasil pembahasan, dapat disimpulkan bahwa majalah Tempo edisi 13-19 April 2015 memuat kepentingan dari pihak ketua partai yang menginkan pemerintahan presiden mengikuti konstitusi partai. Adapun simpulan pada tiga dimensi tersebut adalah (1) pada dimensi tekstual (mikrostruktural), banyak digunakan diksi dan konjungsi, (2) pada dimensi kewacanaan (mesostruktural), diketahui bahwa majalah Tempo tidak terafiliasi dengan pemerintah, (3) pada dimensi praktis sosial budaya (makrostruktural), diketahui terdapat isu politik pada majalah Tempo.

Kata Kunci: hegemoni, majalah Tempo

Departing from the above description, the author raises a problem once as research objectives in this thesis: 1) To describe the hegemony of Jokowi Mega by Textual Dimension (microstructural), 2) To describe the hegemony of Jokowi Mega by discourse Dimension (Mesostructural), 3 ) To describe Mega Jokowi hegemony based on Socio-Cultural Dimensions (Macrostructural) in Tempo magazine April 13 to 19,2015 . This research is a qualitative research. This study uses the approach of critical discourse analaisis (CDA), according to Darma CDA discussion focused on the nature of the contextualization of ideology. The approach on ideology should pay attention to the effects on the shape and meaning and discourse structure that would contribute to and transform ideology. Ideology also affect the use of the language used in the construction of discourse, including the classification and interpretation of social situations (Darma, 2013: 54). Based on the results of the discussion in chapter IV that in the review of the terms of Textual Dimension (microstructural), Discourse Dimensions (Mesostructural), and Practical Social and Cultural Dimension (Macrostructural), it can be concluded that Tempo magazine, April 13 to 19, 2015 includes the 
business of the chairman's party wanting the presidential administration to follow the party constitution. The conclusions in the three dimensions are: 1) Textual Dimensions (microstructural) magazine studied, many uses of diction and conjunctions. 2) Discourse Dimensions (Mesostructural) is a journalist about hegemony reviews conducted by Megawati against the President, and prove that the Tempo is not affiliated with the government. 3) Practical Dimensions of Social and Cultural (Macrostructural), researchers presented data that focuses on the political issues contained in Tempo Magazine.

\section{Keywords: hegemony, Tempo magazine}

PENDAHULUAN Negara adalah suatu daerah atau wilayah dimuka bumi dimana terdapat pemerintahan yang mengatur ekonomi, politik, sosial, budaya, pertahan keamanan dan lain sebagainya. Didalam suatu negara minimal terdapat unsur-unsur negara seperti rakyat, wilayah, pemerintahan yang berdaulat serta pengakuan dari negara lain (Chotib dkk. 2007:03). Secara etimologis istilah "negara" merupakan terjemahan dari kata-kata asing, yaitu state (bahasa Inggris), staat (bahasa Jerman dan Belanda), dan etat (bahasa Prancis). Kata state, staat, dan etat itu diambil oleh orang-orang Eropa dari bahasa Latin pada abad ke-15, yaitu dari kata statum atau status yang berarti keadaan yang tegak dan tetap, atau sesuatu yang bersifat tetap dan tegak. Istilah negara ini muncul bersamaan dengan munculnya istilah lo stato yang dipopulerkan Niccolo Machiavelli lewat bukunya II Principe. Saat itu, lo stato didefinisikan sebagai suatu sistem tugas dan fungsi publik dan alat perlengkapan yang teratur dalam wilayah tertentu.

Pada dasarnya, dalam suatu negara terdapat pemerintahan yang mengatur ekonomi, politik, sosial, budaya. Hal tersebut diatur oleh sistem dan undang-undang yang sudah dibuat dalam negara. Para pemimpin sebagai salah satu pihak yang berkepentingan berada pada garis terdepan dalam mewujudkan perubahan karena dituntut dan diberi tanggung jawab oleh berbagai pihak yang berkepentingan lainnya untuk mampu menjalankan roda organisasi sedemikian rupa. faktor budaya organisasi (culture organization) menjadi penting artinya bagi seorang pemimpin. Budaya organisasi merupakan salah satu faktor penting yang sangat menentukan terhadap berhasil tidaknya organisasi tersebut. Untuk itu, peranan pemimpin dalam upaya membentuk dan membangun budaya organisasi yang kondusif bagi pencapaian tujuan organisasi sangatlah menentukan. Di sini pulalah peran pemimpin menjadi penting dalam proses pemberdayaan (empowerment) karyawan. Mengikuti konsep pemberdayaan yang dikemukakan Pranarka dan Moelijarto (dalam Prijono dan Pranarka, 1996:56-57), maka dituntut kesiapan dan kerelaan pemimpin untuk memberikan atau mengalihkan sebagian kekuasaan, kekuatan atau kemampuan kepada karyawan agar mereka menjadi lebih berdaya.

Indonesia yang mengadopsi kepemimpinan presidensial tidak mengenal adanya lembaga pemegang supremasi teetinggi. Kedaulatan negara dipisahkan menjadi tiga cabang kekuasan, yakni legislatif, eksekutif, dan yudikatif, yang secara ideal diformulasikan sebagai trias politica oleh montesquieu. Pemimpin negara ditetapkan dengan pemilihan umum, dimana rakyat memilih langsung pemimpin negara 
yang lamanya ditentukan oleh konstitusi. Konsentrasi kekuasaan ada pada presiden sebagai kepala negara dan bertanggung jawab kepada presiden.

Sebelum seseorang mencalonkan diri sebagai pemimpin nengara mereka perlu melewati tahapan yang akan membawa calon tersebut ke tangga kepemimpinan, salah satunya dengan masuk pada salah satu partai politik yang ada dinegara tersebut. Disetiap partai juga memiliki pemimpin atau juga disebut ketua umum, dimana ketua umum berhak mencalonkan diri sebagai capres atau salah satu orang dari partai politiknya. Pada tahun 2009 Indonesia memiliki partai politik dengan jumlah besar, 38 partai politik ikut andil dalam menyuarakan idiologi partai yang akan merubah indonesia menjadi lebih baik, (https://id.m.wikipedia.org/wiki/daftar_partai_politik_di_indonesia).

Dengan demikian, suksesor dari partai politik akan meneruskan estafet idiologi partainya untuk menghegemoni suatu negara apabila sukses dalam pemilihan umum di negara tersebut.

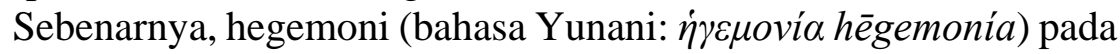
awalnya merujuk pada dominasi (kepemimpinan) suatu negara-kota Yunani terhadap negara-kota lain dan berkembang menjadi dominasi negara terhadap negara lain (Hendarto, 1993:73). Ahli politik Antonio Gramsci mengembangkan makna awal tersebut untuk merujuk pada dominasi suatu kelas sosial terhadap kelas sosial lain dalam masyarakat melalui hegemoni budaya. Hegemoni juga merupakan suatu bentuk kekaisaran yang mengendalikan negara-negara bawahannya dengan kekuasaan (persepsi bahwa ia dapat memaksakan tujuan politiknya), dan bukannya dengan kekuatan (tindakan fisik langsung untuk memaksakan tujuan politiknya).

Hegemoni dapat didefinisikan sebagai dominasi oleh satu kelompok terhadap kelompok lainnya, dengan atau tanpa ancaman kekerasan, sehingga ide-ide yang didiktekan oleh kelompok dominan terhadap kelompok yang didominasi dapat diterima sebagai sesuatu yang wajar (common sense) (Hendarto, 1993:83). Tidak hanya dalam kehidupan sosial hegemoni dapat ditemukan, penulis beranggapan bahwa tindakan higemoni bisa terjadi pada bentuk karangan atau pemberitaan media massa.

Salah satu bentuk karya tulis media massa yang dianggap penulis menunjukkan hegemoni atau isu-isu mempengaruhi antar pemimpin terdapat di majalah Tempo. Majalah Tempo adalah majalah berita mingguan Indonesia yang umumnya meliput berita dan politik. Edisi pertama Tempo diterbitkan pada Maret 1971 yang merupakan majalah pertama yang tidak memiliki afiliasi dengan pemerintah. Selama terbit sampai sekarang Tempo sudah beberapa kali pernah menuliskan laporan yang bersifat investigasi, antara lain pada tahun 1994 meliput tentang kerusuhan Tanjung Priok, pembelian kapal bekas RI dari Jerman, dan sebagainya. Peliputan investigatif tampaknya mulai dipakai wartawan secara serius sejak dekade 1990-an. Sejak reformasi bergulir tahun 1998, pelaporan investigatif banyak mendapat tempat dengan memberitakan kasus-kasus dari elitpolitik negara.

Wacana yang dikonstruksikan oleh wartawan majalah Tempo tidak sepenuhnya netral atau alami melaporkan berita tentang korupsi, dan pelangggaran-pelanggaran hukum, akan tetapi telah dipengaruh oleh ide-ide atau sudut pandang penulis teks (wartawan) dalam menyingkapi 
peristiwa yang dikonstruksikan di dalam pemberitaannya. Sehingga terjadi pro dan kontra pemahaman khalayak terhadap pemberitaan tersebut.

Pada dasarnya sebuah wacana berita media massa merupakan kontsruksi dari realitas-realitas suatu peristiwa sampai membentuk sebuah wacana yang bermakna.

Berangkat dari kecurigaan dan rasa ingin tahu penulis pada majalah Tempo edisi 13 april 2015 yang memuat panas dingin jokowi mega pada saat kongres di Bali, dan Persiapan pidato yang sudah matang dari presiden namun gagal dibacakan menjadi dasar penulis mengangkat judul "Hegemoni Ketua Partai Terhadap Presiden dalam Majalah Tempo Edisi 13 - 19 April 2015".

METODE

\section{PEMBAHASAN}

Jenis penelitian ini adalah penelitian kualitatif. Penelitian kualitatif bertujuan untuk memahami fenomena tentang apa yang dialami oleh subjek penelitian, misalnya perilaku, persepsi, motivasi, tindakan, holistik, dan dengan cara deskripsi dalam bentuk kata-kata dan bahasa pada suatu konteks khusus yang alamiah dan dengan memanfaatkan berbagai metode ilmiah (Moleong, 2009:6).

Penelitian ini menggunakan pendekatan analaisis wacana kritis (AWK), menurut Darma bahasan AWK berfokus pada sifat alami kontekstualisasi idiologi. Penelitian ini melakukan penafsiran terhadap teks berita dalam media massa, Karena bahasa dalam media massa merupakan rekonstruksi dari penulis (wartawan). Untuk itu melalui analisis wacana kritis peneliti mencoba menelisik dan membedah lebih lanjut dengan menggunakan dimensi Norrman Fairclough sebagai acuan untuk mengungkap hegemoni ketua partai terhadap Presiden dalam Majalah Tempo Edisi 13 - 19 April 2015.

Wacana yang dikonstruksikan oleh wartawan majalah Tempo tidak sepenuhnya netral atau alami melaporkan berita tentang korupsi, dan pelangggaran-pelanggaran hukum. Berita tersebut telah dipengaruh oleh ide-ide atau sudut pandang penulis teks (wartawan) dalam menyingkapi peristiwa yang dikonstruksikan di dalam pemberitaannya. Sehingga terjadi pro dan kontra pemahaman khalayak terhadap wacana pemberitaan tersebut.

Majalah Tempo adalah majalah berita mingguan Indonesia yang umumnya meliput berita dan politik. Edisi pertama Tempo diterbitkan pada Maret 1971 yang merupakan majalah pertama yang tidak memiliki afiliasi dengan pemerintah. Selama terbit sampai sekarang Tempo sudah beberapa kali pernah menuliskan laporan yang bersifat investigasi, antara lain pada tahun 1994 meliput tentang kerusuhan Tanjungpriok, pembelian kapal bekas RI dari Jerman, dan sebagainya.

Majalah tersebut di analisis dengan model Norman Fairlough. Adapun penjelasan dari model Norman Fairclough (Eriyanto, 2001: 286) membagi analisis wacana kritis ke dalam tiga dimensi, yakni. Dimensi Tekstual (Mikrostruktural), Dimensi Kewacanan (Mesostruktural), dan Dimensi Praktis Sosial-Budaya (Makrostruktural)

Pada data dibawah ini peneliti akan membahas hegemoni Jokowi Mega berdasarkan dimensi tekstual (mikrostruktural) majalah Tempo edisi 13-19 April 2015 pada wacana yang terdapat di dalamnya. Sedangkan data yang terdapat dalam majalah Tempo edisi 13-19 April 
2015 yang termasuk pada data dimensi tekstual (mikrostruktural) di antaranya adalah sebagai berikut.

Dalam hal gonjang-ganjing hubungan Presiden dan PDIP pada enam bulan pertama pemerintahan Jokowi.

(7.Tempo.31.DTM/DSM)

Diksi yang terdapat pada data di atas menunjukkan bahwa data tersebut termasuk pada dimensi tekstual (mikrostruktural). Pada data tersebut, kata gonjang ganjing adalah sinonim dari kata berguncang dan ketika melihat makna keseluruhan dari kutipan majalah tersebut mengindikasikan adanya kekuasaan di dalam kekuasaan. Partai ingin ikut andil dalam pengambilan keputusan oleh presiden. Adapun pengertian kekuasaan atau hegemoni adalah sebuah pandangan hidup dan cara berpikir yang dominan yang di dalamnya sebuah konsep tentang kenyataan disebarluaskan dalam masyarakat baik secara institusional maupun perorangan. Ideologi mendiktekan seluruh cita rasa, kebiasaan moral, prinsip-prinsip religius dan politik, serta seluruh hubunganhubungan sosial, khususnya dalam makna intelektual dan moral (Nezar, 1999:17).

Data berikutnya, peneliti akan membahas Hegemoni Jokowi Mega berdasarkan dimensi kewacanaan (mesostruktural) majalah Tempo edisi 13-19 April 2015. Sedangkan data yang terdapat dalam majalah Tempo edisi 13-19 April 2015, yang termasuk pada data kewacanaan (mesostruktural) diantaranya adalah sebagai berikut.

Ada tiga alasan mengapa pidato Megawati Soekarnoputri dalam pembukaan kongres Partai Demokrasi Indonesia Perjuangan di bali pekan lalu layak kita sesali. (1.Tempo.31. DKM)

Pada data di atas, yang menjadi acuan dimensi kewacanaan (mesostruktural) adalah pendapat dari wartawan Tempo tentanng hasil kongres di Bali yang dianggapnya mengecewakan. Data tersebut diinterpretasi dari dimensi kewacanaan produksi teks karena majalah Tempo adalah majalah berita mingguan Indonesia yang umumnya meliput berita dan politik. Tempo merupakan majalah pertama yang tidak memiliki afiliasi dengan pemerintah. Namun, pengakuan Jokowi tersebut menjadi bukti adanya hegemoni Mega terhadap dirinya. Adapun pengetian hegemoni adalah sebuah pandangan hidup dan cara berpikir yang dominan. Di dalamnya terdapat sebuah konsep tentang kenyataan disebarluaskan dalam masyarakat baik secara institusional maupun perorangan. Ideologi mendiktekan seluruh cita rasa, kebiasaan moral, prinsip-prinsip religius dan politik, serta seluruh hubungan-hubungan sosial, khususnya dalam makna intelektual dan moral (Nezar, 1999:17).

Kemudian, pada data yang terakhir peneliti akan membahas hegemoni Jokowi Mega berdasarkan dimensi sosial-budaya (makrostruktural) majalah Tempo edisi 13-19 April 2015. Data yang terdapat dalam majalah Tempo edisi 13-19 April 2015 termasuk pada data dimensi sosial-budaya (makrostruktural) diantaranya adalah sebagai berikut. 
Aspek pertama yang layak dikecam dari orasi itu adalah bahwa Megawati mengabaikan sebuah prinsip penting: loyalitas terhadap partai berahir ketika loyalitas kepada negara dimulai. (4.Tempo.31.DSM)

Data tersebut diklasifikasikan pada dimensi praktis sosial budaya (makrostruktural). Data terbut mebahas politik. Hal tersebut terbukti pada kutipan "loyalitas terhadap partai berahir ketika loyalitas kepada negara dimulai". Artinya, seorang calon presiden yang dicalonkan oleh partai berhak menentukan sebuah keputusan ketika terpilih sebagai presiden dan tidak lagi mengambil keputusan dibawah konstitusi partai. Data yang menunjukkan hegemoni adalah kekeceaan Megawati pada Presiden ketika menuntut Presiden untuk taat terhadap konstitusi partai. Hegemoni adalah sebuah pandangan hidup dan cara berpikir yang dominan. Di dalamnya terdapat sebuah konsep tentang kenyataan disebarluaskan dalam masyarakat baik secara institusional maupun perorangan. Ideologi mendiktekan seluruh cita rasa, kebiasaan moral, prinsip-prinsip religius dan politik, serta seluruh hubungan-hubungan sosial, khususnya dalam makna intelektual dan moral (Nezar, 1999:17).

SIMPULAN

Berdasarkan hasil pembahasan yang ditinjau dari segi dimensi tekstual (mikrostruktural), dimensi kewacanaan (mesostruktural), dan dimensi praktis sosial budaya (makrostruktural), dapat disimpulkan bahwa majalah Tempo edisi 13-19 April 2015 memuat kepentigan dari pihak ketua partai. Pihak tersebut menginginkan pemerinahan presiden mengikuti konstitusi partai. Adapun simpulan pada tiga dimensi tersebut adalah sebagai berikut.

(1) Banyak digunakan diksi dan konjungsi pada dimensi tekstual (mikrostruktural).

(2) Berdasarkan ulasan wartawan tentang hegemoni yang dilakukan oleh Megawati terhadap Presiden, terbukti bahwa majalah Tempo tidak terafiliasi dengan pemerintah pada dimensi kewacanaan (mesostruktural).

(3) Peneliti menyajikan data yang menitik beratkan pada isu politik yang terdapat pada majalah Tempo pada dimensi praktis sosial budaya.

\section{DAFTAR PUSTAKA}

Chotib dkk. 2007. Kewarganegaraan 1 Menuju Masyarakat Madani. Jakarta: Yudhistira.

Eriyanto. 2001. Analisis Wacana: Pengantar Analisis Teks Media. Yogyakarta: LKIS

Fairclough, Norman. 1995. Critical Disqurse Anylysis. London: Longman Group Ltd.

Hendarto, Heru. 1993. Mengenal Konsep Hegemoni Gramsci: Dalam Diskursus Kemasyarakatan dan Kemanusiaan. Gramedia. Jakarta

https://id.m.wikipedia.org/wiki/daftar_parta i_politik_di_indonesia
Moleong, L. J. 2007. Metode Penelitian Kualitatif. Bandung: Remaja Rosdakarya.

Patria, Nezar dan Andi Arief. 1999. Antonio Gramsci, Negara Dan Hegemoni. Yogyakarta: Pustaka Pelajar Offset

Prijono, Onny S. dan A.M.W. Pranarka (penyunting). 1996. Pemberdayaan: Konsep, Kebijakan, dan Implementasi. Jakarta: Centre For Strategic and International Studies.

Tempo. 2015. Panas Dingin Jokowi Mega Edisi 13-19 April 2015. Jakarta: PT. Tempo Inti Media tbk. 